\title{
Computational fragment-based drug design to explore the hydrophobic subpocket of the mitotic kinesin Eg5 allosteric binding site
}

\author{
Ksenia Oguievetskaia ${ }^{*}$, Laetitia Martin-Chanas ${ }^{* \dagger}$, Artem Vorotyntsev, Olivia Doppelt-Azeroual, Xavier Brotel,
} Stewart A Adcock, Alexandre G de Brevern, Francois Delfaud, Fabrice Moriaud

From 5th German Conference on Cheminformatics: 23. CIC-Workshop

Goslar, Germany. 8-10 November 2009

Eg5, a mitotic kinesin exclusively involved in the formation and function of the mitotic spindle has attracted interest as an anticancer drug target. Eg5 is co-crystallized with several inhibitors bound to its allosteric binding pocket. Each of these occupies a pocket formed by loop5/helix $\alpha 2$. Recently designed inhibitors additionally occupy a hydrophobic pocket of this site. The goal of the present study was to identify new fragments which fill this hydrophobic pocket and might be interesting chemical moieties to design new inhibitors.

We've used the fragment based protocol of MEDSuMo which exploits the whole PDB on the basis that similar protein surfaces might bind the same fragment. The MED-SuMo software is able to compare and superimpose similar protein-ligand interaction surfaces at PDB scale. Protein-fragment complexes are encoded as MED-Portions by cross-mining 3D PDB ligand structures with fragment-like PubChem molecules. Inhibitors are designed by hybridising MED-Portions with MEDHybridise.

Without using the known Eg5 PDB ligands that occupy the hydrophobic pocket, we've predicted new potential ligands that would fill simultaneously both pockets. Some of the latter are identified in libraries of synthetically accessible molecules by the MED-Search software.
doi:10.1186/1758-2946-2-S1-P29

Cite this article as: Oguievetskaia et al:: Computational fragment-based drug design to explore the hydrophobic subpocket of the mitotic kinesin Eg5 allosteric binding site. Journal of Cheminformatics 2010 2(Suppl 1):P29

\footnotetext{
Publish with ChemistryCentral and every scientist can read your work free of charge

"Open access provides opportunities to our colleagues in other parts of the globe, by allowing anyone to view the content free of charge." W. Jeffery Hurst, The Hershey Company.

- available free of charge to the entire scientific community

- peer reviewed and published immediately upon acceptance

- cited in PubMed and archived on PubMed Central

- yours - you keep the copyright

Submit your manuscript here:

http://www.chemistrycentral.com/manuscript/ 